\title{
Effects of adrenalectomy on taste aversion learning
}

\author{
ROBERT ADER, LEE J. GROTA, and ROBERT BUCKLAND \\ University of Rochester School of Medicine and Dentistry, Rochester, New York 14642
}

\begin{abstract}
Adrenalectomized (ADX) rats were maintained on a saline drinking solution and daily subcutaneous injections of low doses of dexamethasone plus aldosterone. Sham-operated control and ADX animals were conditioned by pairing consumption of a saccharin-flavored drinking solution with the intraperitoneal injection of cyclophosphamide. Nonconditioned animals received only cyclophosphamide. An attenuation of the neophobic response to the initial exposure to saccharin in ADX animals was attributed to the need to consume salt in these animals. ADX and control groups displayed a significant aversion to saccharin presented 3 days after conditioning. The results indicate that the release of adrenocortical steroids in response to the CS or the UCS is not a necessary condition for the acquisition of a taste aversion.
\end{abstract}

Several studies have examined the behavior of adrenalectomized animals in a taste aversion conditioning paradigm. Most of these studies (e.g., Cullen, 1970; Frumkin, 1971, 1975a, 1975b, Trent \& Kalat, 1977) have been concerned primarily with the modifiability of specific, hormonally induced hungers or a definition of the limitations of taste aversion learning in the face of physiologic needs that may be corrected by consummatory responses. Of necessity, such experiments have capitalized on the adrenalectomized animal's need for salt and do not, therefore, provide definitive information regarding the capacity of adrenalectomized animals to acquire a taste aversion.

In a study by Frumkin (1975b), rats were adrenalectomized before conditioning and subsequently poisoned with LiCL shortly after drinking either a saccharin or $\mathrm{NaCL}$ solution. Conditioned and nonconditioned adrenalectomized and shamadrenalectomized animals were later tested for the acquisition of a taste aversion by allowing them to choose between saccharin and NaCL solutions. Adrenalectomized animals failed to show an aversion to the salt solution, and the consumption of saccharin was so depressed in all adrenalectomized animals (saccharin was not made up in a saline solution) that clear evidence of an aversion to saccharin was not demonstrated. As this report

This research was supported by Grant HD-09977 and by a Research Scientist Award (K5-MH-06318) to the senior author from the United States Public Health Service. Robert Buckland was supported by a Summer Medical Student Research Fellowship. Dr. Buckland is currently at Dartmouth Medical School, Hanover, New Hampshire. Address reprint requests to Robert Ader, Department of Psychiatry, University of Rochester Medical Center, Rochester, New York 14642. suggests, it is likely that the adrenalectomized animal's need for salt could have masked the expression of an acquired aversion to saccharin.

In contrast to the permanent salt deficiency induced by adrenalectomy, Trent and Kalat (1977) produced a temporary deficiency by the injection of either Formalin or aldosterone. The rats were then intubated with $\mathrm{LiCL}$ following consumption of sucrose and $\mathrm{NaCL}$ drinking solutions provided sequentially. One week later, the animals (not then under the influence of either Formalin or aldosterone) were tested for the acquisition of a taste aversion by providing them with a choice between sucrose and water or $\mathrm{NaCL}$ and water. Under these conditions, all animals displayed an aversion to both sucrose and NaCL.

There is one study (Garcia \& Kimmeldorf, 1960) which speaks directly to the capacity of adrenalectomized animals to acquire a taste aversion unconfounded by (1) the adrenalectomized animal's physiologic need for salt or (2) the interaction (the potential inability to discriminate) between $\mathrm{NaCL}$ and LiCL used as conditioned and unconditioned stimuli in the conditioning paradigm (Nachman, 1962, 1963). Adrenalectomized animals were exposed to whole-body $\mathrm{X}$-irradiation during a period when they were drinking a saline solution to which saccharin had been added. When tested 1 day later, adrenalectomized animals showed a significant aversion to the saccharin drinking solution.

Recently, attention has been focused on the hormonal concomitants and mediation of taste aversion learning with particular emphasis on the pituitary-adrenal system (Ader, 1976; Braveman, 1977; Hennessy, Smotherman, \& Levine, 1976; Smotherman, Hennessy, \& Levine, 1976). We therefore examined the effects of adrenalectomy on 
the acquisition of a drug-induced taste aversion, attending to potentially confounding issues which have existed in one or another of the previously published reports, e.g., the salt-deficient and debilitated state of the animals and the altered sensory thresholds that can accompany adrenal insufficiency (Henkin, 1970).

\section{METHOD}

Charles River (CD) male rats, approximately 90 days of age, were individually caged under conditions of constant temperature $\left(21 \pm 2^{\circ}\right)$ and a 12-h light-dark cycle (light from 6 a.m. to 6 p.m.) with food and water provided ad lib. Bilateral adrenalectomies were performed on 45 animals 10 to 14 days before conditioning, while control animals $(N=33)$ experienced a sham operation. Adrenalectomized (ADX) animals were thereafter provided with a $.9 \%$ saline in tap-water drinking solution. To further obviate the debilitating effects of adrenalectomy, ADX animals were also injected subcutaneously with low doses of dexamethasone $(2 \mu \mathrm{g})$ plus aldosterone $(10 \mu \mathrm{g})$ in $.2 \mathrm{ml}$ sesame oil each afternoon. Control (sham) animals continued drinking plain water but received daily injections of sesame oil. The synthetic glucocorticoid, dexamethasone, was administered to maintain ADX animals in a healthy state without exerting any influence on pituitary-adrenal reactivity; aldosterone was administered to counteract the effects of adrenalectomy on the detection and perception of gustatory and/or olfactory stimuli (Henkin, 1970). Using the methods described by Glick, Von Redlich, and Levine (1964), bilateral adrenalectomies were confirmed by postexperiment determinations of plasma corticosterone concentrations sampled late in the afternoon, i.e., at the peak in the rats' 24-h adrenocortical rhythm. ADX rats had a mean corticosterone level of $4.7 \pm .2$ as compared with a mean of $18.5 \pm 1.3$ in sham-operated controls $[t(76)=10.49, p<.01]$.

All animals were gradually adapted to a restricted drinking schedule. The saline or plain water drinking solutions were made available for a decreasing amount of time over an 8-day period, until the total daily allotment of fluid was confined to a single 15-min drinking period beginning at 1000 to $1015 \mathrm{~h}$ each day. After 5 days under this regimen, conditioning was introduced.

Control $(\mathbf{N}=23)$ and ADX $(\mathbf{N}=30)$ animals were conditioned by providing them with a $.1 \%$ solution of sodium saccharin in tap water or saline, respectively, in place of their regularly scheduled drinking solution. In a pilot study, it was established that ADX animals do, in fact, prefer saccharin in saline to a plain saline drinking solution, which is consistent with the observations of Garcia and Kimmeldorf (1960). A nonconditioned sample of $\operatorname{ADX}(N=15)$ and sham $(N=10)$ animals received saline or plain water that was not flavored with saccharin. Thirty minutes after the 15-min drinking period, all animals were injected intraperitoneally with $50 \mathrm{mg} / \mathrm{kg}$ cyclophosphamide, a toxic substance with noxious gastrointestinal effects. During the following 2 recovery days, all ADX and sham animals were again supplied with saline or plain water, respectively. On the next (test) day, half the ADX and control animals that had experienced the pairing of saccharin consumption and cyclophosphamide were provided with the saccharin drinking solution (Group C) and half were supplied with their usual drinking solution (Group Co). Nonconditioned (NC) animals were also provided with the saccharin-flavored drinking solution. Fluid consumption was measured daily.

The available $\mathbf{N}$ was not considered sufficient for the inclusion of a comparison group of nonconditioned rats provided with saccharin and injected with placebo instead of cyclophosphamide. This decision was based on the following considerations: cyclophosphamide has been used in several studies of taste aversion, and it is clear that it is the drug and not the IP injection of either saline or distilled water that induces a taste aversion; we had already confirmed the preference of ADX animals for a saline solution containing saccharin; NC animals that received their initial exposure to saccharin on the test day were expected to evidence some neophobia and would, therefore, constitute a more severe control condition for assessing any differences in saccharin consumption that resulted from the pairing of saccharin with cyclophosphamide; and it was considered necessary to determine if cyclophosphamide administered to adrenalectomized animals would decrease fluid consumption, per se.

\section{RESULTS AND DISCUSSION}

Fluid intake for the conditioned and nonconditioned ADX and sham-operated control animals is shown in Figure 1. It is evident that adrenalectomized animals as well as controls are capable of expressing an aversion to a distinctively flavored drinking solution that has been paired with cyclophosphamide on the basis of a single pairing of these events. The intake of saccharin by shamoperated $\mathrm{C}$ animals is significantly lower than that in NC animals $[t(19)=3.33, p<.01]$. This difference occurred despite the fact that the consumption of saccharin by NC controls on the test day is depressed relative to their intake of plain water on the preceding "recovery" days. In ADX animals, too, consumption of saccharin by Group $C$ is significantly less than that of Group $\mathrm{NC}[\mathrm{t}(28)=6.34, \mathrm{p}<.01]$

Although the data would suggest that acquisition of a taste aversion is potentiated by adrenalectomy, this impression might be explained by reference to the overall fluid intake and the degree of neophobia expressed by ADX and control animals. Relative to the baseline consumption of plain water, sham-operated controls first provided with

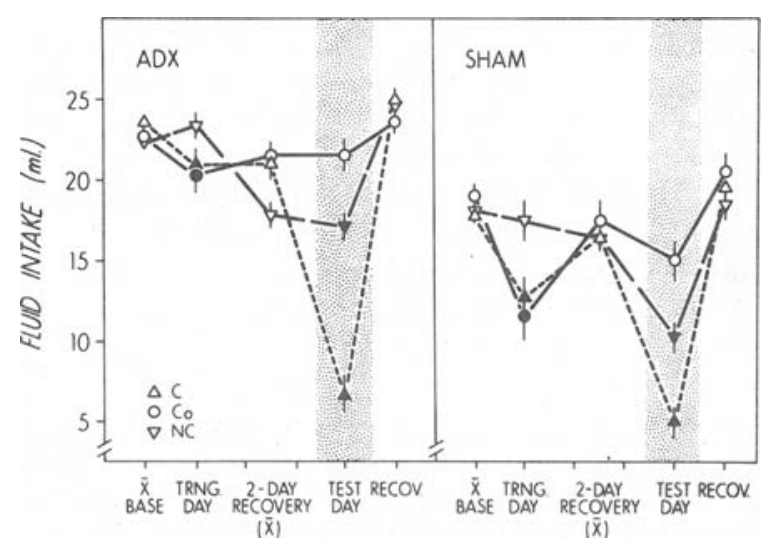

Figure 1. Mean ( \pm S.E.M.) fluid consumption of conditioned and nonconditioned (NC) adrenalectomized (ADX) and shamoperated control animals. Conditioned animals were divided into those that did $(C)$ and those that did not $(\mathrm{Co})$ receive saccharin on the test day. Filled symbols indicate the drinking periods during which saccharin was presented. 
saccharin on the training day (Groups $\dot{C}$ and Co) showed a $31.9 \%$ reduction in fluid consumption; ADX animals displayed only a $12.7 \%$ reduction in fluid consumption under the same conditions. The percentage reduction difference between the conditioned ADX and sham animals is statistically significant $[\mathrm{t}(51)=3.32, \mathrm{p}<.01]$. Nonconditioned animals were first exposed to the saccharin solution on the test day. Relative to the intake of saline or plain water on the preceding "recovery" days, controls showed a $36.8 \%$ reduction and ADX animals showed a $2.9 \%$ reduction in fluid consumption. This difference, too, is statistically significant $[\mathrm{t}(23)=5.86, \mathrm{p}<.01]$.

The attentuated neophobia resulting from adrenalectomy may, perhaps, be parsimoniously explained by the physiological need for adrenalectomized animals to consume the saline drinking solution. This is consistent with the somewhat greater overall fluid consumption shown by ADX relative to control amimals. It should be noted that, relative to their intake of saline or plain water during the "recovery" days, conditioned ADX and sham animals actually showed a comparable reduction $(68.1 \%$ and $66.9 \%$, respectively) in their consumption of the saccharin solution on the test day. This observation, taken together with the absence of any cyclophosphamide-induced reduction of fluid consumption in adrenalectomized animals, provides no grounds for supposing that the observed effects of adrenalectomy on the acquisition of a taste aversion are attributable to qualitative or quantitative differences between ADX and control animals in their response to cyclophosphamide. Using conditioned and unconditioned stimuli uncontaminated by the special requirements of adrenalectomized animals to adopt behaviors calculated to reinstate homeostatic balance, the present data, in keeping with the observations of Garcia and Kimmeldorf (1960), indicate that adrenalectomized animals are capable of taste aversion learning.

There are data which indicate that elevations in plasma corticosterone accompany the conditioning of a taste aversion and that elevations in adrenocortical steroids can be conditioned in a taste aversion paradigm (Ader, 1976). There are also data indicating that the experimental manipulation of pituitary-adrenal activity can influence the acquisition and/or the extinction of a taste aversion (Hennessy et al., 1976; Smotherman et al., 1976). Like the injection of toxic pharmacologic agents such as cyclophosphamide and $\mathrm{LiCl}, \mathrm{X}$ irradiation also elicits an elevation of steroid levels (Hameed \& Haley, 1964). While such changes in adrenocortical activity in response to novel taste stimuli and toxic stimuli occur and may modify the behavioral expression of a taste aversion, the present results indicate that adrenocortical responses are not critical for the acquisition of a conditioned taste aversion. The extraadrenal effects of ACTH on taste aversion behavior, however, remain to be further elucidated (Rigter \& Popping, 1976; deWied, 1969).

\section{REFERENCES}

ADER, R. Conditioned adrenocortical steroid elevations in the rat. Journal of Comparative and Physiological Psychology, 1976, 90, 1156-1163.

BRAVEMAN, N. S. What studies on preexposure to pharmacological agents tell us about the nature of the aversion-inducing agent. In L. M. Barker, M. R. Best, \& M. Domjan (Eds.), Learning mechanisms in food selection. Houston: Baylor University Press, 1977.

Cullen, J. W. Modification of $\mathrm{NaCl}$ appetite in the adrenalectomized rat consequent to extensive $\mathrm{LiCl}$ poisoning. Journal of Comparative and Physiological Psychology, 1970, 72, 79-84.

FrUMKIN, K. Interaction of $\mathrm{LiCl}$ aversion and sodium-specific hunger in the adrenalectomized rat. Journal of Comparative and Physiological Psychology, 1971, 75, 32-40.

FRUMKIN, K. Effects of deprivation schedule on the maintenance of a preoperative salt aversion by adrenalectomized rats. Physiological Psychology, 1975, 3, 101-106. (a)

FrUMkIN, K. Failure of sodium- and calcium-deficient rats to acquire conditioned taste aversions to the object of their specific hunger. Journal of Comparative and Physiological Psychology, 1975, 89, 329-339. (b)

GaRCiA, J., \& Kimmeldorf, D. J. Some factors which influence radiation-conditioned behavior of rats. Radiation Research, 1960, 12, 719-727.

Glick, D., von Redlich, D., \& Levine, S. Fluorometric determination of corticosterone and cortisol in 0.02-0.05 milliliters of plasma or sub-milligram samples of adrenal tissue. Endocrinology, 1964, 74, 653-655.

Hameed, J. M., \& Haley, T. J. Plasma and adrenal gland corticosterone levels after X-ray exposure in rats. Radiation Research, 1964, 23, 620-629.

Henkin, R. I. The effects of corticosteroids and ACTH on sensory systems. In D. deWied \& J. A. W. N. Weijnen (Eds.), Pituitary, adrenal and the brain. Progress in brain research (Vol. 32). Amsterdam: Elsevier, 1970.

Hennessy, J. W., Smotherman, W. P., \& Levine, S. Conditioned taste aversion and the pituitary-adrenal system. Behavioral Biology, 1976, 16, 413-424.

NaChMan, M. Taste preference for sodium salts by adrenalectomized rats. Journal of Comparative and Physiological Psychology, 1962, 55, 1124-1129.

NACHMAN, M. Learned aversion to the taste of lithium chloride and generalization to other salts. Journal of Comparative and Physiological Psychology, 1963, 56, 343-349.

RigTer, H., \& Popping, A. Hormonal influences on the extinction of conditioned taste aversion. Psycopharmacologia, 1976, 46, 255-261.

Smotherman, W. P., Hennessy, J. W., \& Levine, S. Plasma corticosterone levels as an index of the strength of illness induced taste aversions. Physiology \& Behavior, 1976, 17, 903-908.

Trent, A. M., \& Kalat, J. W. Lack of effect of specific sodium hunger on learned aversions to sodium and sucrose. Animal Learning \& Behavior, 1977, 5, 243-246.

DEWIED, D. Effects of peptide hormones on behavior. In W. F. Ganong \& L. Martini (Eds.), Frontiers in neuroendocrinology. New York: Oxford, 1969

NOTE

1. Cyclophosphamide was generously supplied by the Mead Johnson Research Center, Evansville, Indiana.

(Received for publication November 8, 1977; revision accepted February 27, 1978.) 